Research Paper

\title{
Do investors price industry risk? Evidence from the cross-section of the oil industry
}

\author{
Sofia B. Ramos, ${ }^{1}$ Abderrahim Taamouti, ${ }^{2}$ Helena Veiga ${ }^{3,4}$ \\ and Chih-Wei Wang ${ }^{5}$ \\ ${ }^{1}$ ESSEC Business School, 3 Avenue Bernard Hirsch, 95021 Cergy-Pontoise, France; \\ email: ramos@essec.edu \\ ${ }^{2}$ Durham University Business School, Mill Hill Lane, Durham DH1 3LB, UK; \\ email: abderrahim.taamouti@ durham.ac.uk \\ ${ }^{3}$ Department of Statistics and Instituto Flores de Lemus, Universidad Carlos III de Madrid, \\ C/ Madrid 126, 28903 Getafe (Madrid), Spain \\ ${ }^{4}$ Research Unit-UNIDE, Instituto Universitário de Lisboa (ISCTE-IUL), \\ Avenida das Forças Armadas, 1649-026 Lisboa, Portugal; \\ email: mhveiga@est-econ.uc3m.es \\ ${ }^{5}$ Department of Finance, College of Management, National Sun Yat-sen University, \\ 70 Lianhai Road, Gushan District, Kaohsiung City 804, Taiwan; \\ email: chwang@mail.nsysu.edu.tw
}

(Received December 11, 2015; revised August 17, 2016; accepted August 19, 2016)

\section{ABSTRACT}

Recent research identifies several industry-related patterns that standard asset pricing models cannot explain effectively. This paper investigates what explains the crosssection of returns of firms in the oil industry and, in particular, how well an oil factor performs in comparison with the common systematic factors identified in the literature. We conduct a time series analysis and demonstrate that the oil factor has substantial explanatory power over traditional factors. A cross-sectional regression shows that the size, momentum and oil factors are associated with a positive risk premium and are able to explain the cross-sectional variation in stock returns in the 
oil industry. Our results suggest that investors demand compensation for the exposure to oil price changes, which has implications for the computation of the cost of equity.

Keywords: anomalies; asset pricing; cross-sectional tests; oil industry; oil prices; time series tests.

\section{INTRODUCTION}

How important are industry risks in asset pricing? Despite the longstanding academic interest in asset pricing, the importance of industry-specific features has been overlooked. Thus far, banking is the only sector that has been the object of such analysis. Viale et al (2009) find no evidence that factors such as size and book-to-market ratios are priced in the banking sector; however, shocks to the yield curve often explain banking stock returns. Baek and Bilson (2015) find an interest rate risk premium for financial firms. Adrian et al (2015) test a five-factor asset pricing model that includes a factor based on the return on equity of the financial sector and the spread of the return of the financial sector and market portfolio. Gandhi and Lustig (2015) document a size effect in bank stock returns that is different from the market capitalization effects that have been documented in nonfinancial stock returns. They attribute the size-dependent exposure to bank-specific tail risk, that is, to the fact that "large banks are too big to fail". Overall, this evidence suggests that investors give importance to industry-specific risks.

In this paper, we analyze the case of a commodity-dependent industry: the oil industry. Commodity price risk is important for companies in natural resource industries (see Hong and Sarkar 2008). For instance, firm profitability and operating decisions (eg, exploration and investment decisions) all depend on commodity prices and, as such, may affect expected stock returns. From a theoretical perspective, the intertemporal capital asset pricing model (ICAPM) proposed by Merton (1973) states that, in addition to the market beta, if investment opportunities change over time, then assets' exposures to these changes are important determinants of average returns. We explore the asset pricing implications of this commodity dependence and whether investors demand compensation for this exposure. Given that the price of oil has such a pivotal role in this industry, we test the hypothesis that oil price changes are important for the average returns of the oil and natural gas industry. Further, the case of oil is doubly interesting because oil has been proposed as a systematic factor (see Chen et al 1986). The literature's findings are not unanimous: early results do not support the idea that oil is an important factor for financial markets (Chen et al 1986; Ferson and Harvey 1994; Hamao 1989; Huang et al 1996), but, since the work of Driesprong et al (2008), it has been acknowledged that oil returns have predictive power for financial markets.

We begin our analysis by examining how the existing standard asset pricing factors perform when pricing industry-related risk. We then investigate the hypothesis that oil 
exposure is priced in the cross-section. Using time series analysis, prior studies have found that oil is a key factor in oil industry returns, but such research has not included cross-sectional analysis. Such analysis is critical to understanding what explains the average returns of firms in the oil industry, and whether investors price the risk of commodity dependence. ${ }^{1}$

Using a sample of 203 oil and natural gas firms for the period 1988-2012, we first build portfolios that we sort based on exposure to oil price changes. We find that raw value-weighted portfolio annualized returns for firms in the lowest oil beta decile are, on average, $0.0788 \%$ monthly, whereas average value-weighted portfolio returns for firms in the highest oil beta decile are greater than or equal to $0.765 \%$ monthly. The spread between high- and low-oil-sensitivity portfolios is $9.45 \%$ annually, while that for a portfolio with equally weighted values is $9.18 \%$ annually. Overall, this is our first piece of evidence that returns increase when exposure to oil changes. This motivates us to continue our analysis.

To thoroughly understand the importance of the oil factor in explaining the returns of firms in the oil industry, we consider both time series and cross-sectional analyses based on the Fama-French three-factor model; this is augmented with the momentum factor of Carhart (1997) and an oil-related factor. According to time series analysis, the oil factor has substantial explanatory power over the common factors. The $R^{2}$ value improves substantially and varies between $30.9 \%$ and $55.5 \%$ for low oil sensitivity and between $49.7 \%$ and $72.6 \%$ for high oil sensitivity when we control for the oil factor; by contrast, it varies between $26 \%$ and $46.5 \%$ for low oil sensitivity and between $22.9 \%$ and $35.2 \%$ for high oil sensitivity when the oil factor is excluded. A crosssectional analysis shows the oil factor presents a positive and statistically significant risk premium; thus, the results suggest that investors demand compensation for the exposure of firms to oil price changes. In addition, we find that size and momentum factors explain average returns in the industry by presenting a positive risk premium. The oil factor risk compensation remains when we control for many other well-known factors, such as profitability, liquidity and term structure factors.

So far, there is no evidence of whether standard factors are able to explain the average stock returns in the oil industry. Moreover, there is no proof that anomalies exist

\footnotetext{
${ }^{1}$ One strand of the literature uses arbitrage pricing theory or vector autoregression (VAR) models to analyze the risk factors of the oil industry. These papers document that oil is an important driver in the oil industry (see, for example, Al-Mudaf and Goodwin 1993; Boyer and Filion 2007; El-Sharif et al 2005; Faff and Brailsford 1999; Hammoudeh and Li 2004; Oberndorfer 2009; Park and Ratti 2008; Ramos and Veiga 2011; Ramos et al 2014; Sadorsky 2001). However, all of these papers provide time series analyses.
} 
in the oil industry. We are the first to document such evidence, showing that market risk is not rewarded. This paper contributes to the literature by providing evidence of the implications for industry features and asset pricing, suggesting that investors price specific industry risks such as commodity dependence. We find, particularly in the case of the oil industry, that investors demand compensation for oil price risk. Our findings are similar to those obtained in the banking sector, where specific industry factors directly related to profitability have also been found to be priced. For instance, Viale et al (2009) argue that the shape of the yield curve is important in explaining prospects for bank stocks. The sensitivity to interest rate changes, proposed as a factor by Baek and Bilson (2015), is also a variable related to the profitability of the banking sector. Overall, as in the case of oil firms, the evidence is supportive of market premiums on risks that affect profitability and expected stock returns.

Our findings are also relevant for constructing portfolios exposed to oil price risk. The results show that a portfolio based on oil sensitivity that tries to capture the oil premium would yield abnormal returns. In our work, the results show a spread between portfolios of firms with high sensitivity to oil versus firms with low sensitivity to oil. An investment strategy could be developed in order to capture the premium giving more weight to stocks with higher oil sensitivity. ${ }^{2}$

The remainder of this paper is organized as follows. In Section 2, we briefly summarize the relevant literature. In Section 3, we discuss our data and the construction of portfolio returns. Section 4 explains our methodology, particularly the time series and cross-sectional regressions under consideration. Section 5 reports the results of time series and cross-sectional analyses for both traditional empirical asset pricing models and those that include oil as a main factor. Section 6 reports other results that we obtain after controlling for additional known risk factors. We conclude the paper in Section 7.

\section{REVIEW OF THE LITERATURE}

The vast literature on asset pricing begins with the groundbreaking works of Black (1972), Lintner (1965) and Sharpe (1964). Miller (1999) is one of the first works to recognize the consensus among academics that a single factor, known as the market beta, is insufficient to describe the cross-section of expected returns. Several other papers document anomalies and other variables that appear to explain the cross-section of returns, such as the Monday dummy (French 1980), the January dummy (Reinganum

\footnotetext{
${ }^{2}$ This can be compared with a recent investment approach in the asset management industry named "smart beta investing". In this investment style, the weight of the securities in the index is not given by market capitalization, that is considered "dumb", as it gives more weight to overvalued securities, which will yield lower future returns to investors. Weights are given by smarter approaches that try to capture abnormal returns given by a well-known factor.
} 
1983; Roll 1983), the price-earnings ratio (Ball 1978; Basu 1977; Jaffe et al 1989), firm size (Banz 1981; Basu 1983), long-term reversals (De Bondt and Thaler 1985), the book-to-market ratio (Rosenberg et al 1985; Stattman 1980), leverage (Bhandari 1988) and momentum (Jegadeesh 1990; Jegadeesh and Titman 1993).

A turning point in the research occurred with the works of Fama and French (1992, 1993, 1996). These showed that firm size and the book-to-market ratio explain the cross-sectional variation in equity returns and proposed a three-factor model that adds returns of portfolios based on market capitalization and book-to-market ratios to the market portfolio.

Our work is closely related to the bulk of the literature that focuses on how industry specificities affect asset pricing. A series of papers indicate the industry features that might impact asset pricing (see, for example, Asness et al 2000; Cohen et al 2003; Hou 2003; Moskowitz and Grinblatt 1999). Hou and Robinson (2006) focus on industry features such as industry concentration and posit that the structure of product markets may affect stock returns. Those researchers argue that operating decisions arise from an equilibrium in the product market that potentially reflects strategic interactions among market participants. Therefore, the structure of product markets may affect the risk of a firm's cashflows and, hence, a firm's equilibrium rate of return. If the structure of product markets affects asset prices, then either the market structure affects risk directly or it is somehow correlated with investor perceptions in a way that links it to behavioral phenomenons. The results of those studies reveal that firms in concentrated industries earn lower returns. Lewellen et al (2010) show that several risk-based asset pricing models are rejected because they fail to explain the crosssection of returns on industry portfolios, while Chou et al (2012) show that industry portfolio returns cannot be fully explained by well-known asset pricing models.

Another strand of the literature investigates whether the Fama-French three-factor model is a good asset pricing model in specific industries, such as banking. Viale et al (2009) document that firm-specific factors such as size and book-to-market ratios cannot explain bank stock returns, while stock market excess returns and shocks to the slope of the yield curve are priced in the cross-section of bank stock returns. Zeng et al (2014) support the existence of a banking factor that explains the returns of firms in the US market. Elyasiani et al (2007) examine market betas for US banks and report that the systematic risk exposure of larger banks is greater than that of smaller banks. Adrian et al (2015) propose a five-factor asset pricing model that includes a factor based on the return on equity (ROE) of the financial sector (a high-minus-low ROE portfolio) and the return of the financial sector minus the market return. Gandhi and Lustig (2015) document a size effect in bank stock returns that is different from the market capitalization effects that have been documented in nonfinancial stock returns. They attribute this size-dependent exposure to bank-specific tail risk. Overall, the evidence supports that industry risks might impact the cross-sectional returns. 
Although several studies have reported that oil explains the time series returns of firms in the oil industry, the research on what explains the average returns of firms in the oil industry is missing. Our aim in this paper is to investigate the hypothesis that investors demand compensation for the strong economic dependence on oil price. Oil price is widely acknowledged to influence profitability and expansion/closing decisions; consequently, it will affect expected stock returns in the industry.

HyPOTHESIs. The oil factor loading is priced in the cross-section of returns of firms in the oil industry.

Moreover, we are interested in understanding how commodity price risk relates to other well-known asset pricing factors. If the presumption that firm profitability is affected by oil prices is correct, then when commodity price increases, market capitalization increases and the book-to-market ratio decreases. Thus, if commodity price changes matter for market returns, we might observe simultaneously that large firms and growth firms provide abnormal returns. The problem is challenging, as firm size and the book-to-market ratio have been found to be priced risk factors in the literature. This paper aims to both understand whether commodity is a priced factor and disentangle its effect from those of the book-to-market and size factors.

We know little about whether the so-called anomalies are present in the oil industry, and, in particular, whether the specificities of the oil industry as an oil-dependence risk provides a risk premium. ${ }^{3}$ Therefore, our primary objective in this paper is to fill this gap in the literature and investigate whether the oil factor is priced in the cross-section of returns.

\section{DATA AND PORTFOLIO RETURNS}

\subsection{Data}

We select firms whose business activity is directly related to crude oil. Those firms are from industries with the following Standard Industry Classification (SIC) codes: 1311, 138 (including 1381, 1382 and 1389), 2911, 2990 and 3533. They correspond to a total of seven oil-related industries, including Crude Petroleum and Natural Gas (SIC code 1311); Drilling Oil and Gas Wells (SIC code 1381); Oil and Gas Field Exploration Services (SIC code 1382); Oil and Gas Field Services, NEC (SIC code 1389); Petroleum Refining (SIC code 2911); Miscellaneous Products of Petroleum and Coal (SIC code 2990); and Oil and Gas Field Machinery and Equipment (SIC code 3533).

\footnotetext{
${ }^{3}$ A risk premium in commodities markets is also named for differences in spot and futures markets (see, for example, Benth and Meyer-Brandis 2009; Veraart and Veraart 2013).
} 
From Compustat and the Center for Research in Security Prices (CRSP), we extract data on the following monthly company items: the adjusted (raw) return at the end of the month, the market capitalization and the book-to-market ratio. The sample period is from December 1988 to December 2012. Similarly to previous works, we impose some filters on the sample, such that we retain only firms that have Compustat data for more than two consecutive years. However, we note that there is no requirement that firms have data available for the entire sample period; thus, we have an unbalanced panel data set. We include all observations for companies covered in this database as long as the information is available for the sample period (1988-2012) (see, for example, Viale et al 2009). ${ }^{4}$

Table 1 presents the descriptive statistics by SIC code. In particular, the table provides statistics on the number of firms, the market capitalization, the book-tomarket ratio and the monthly raw returns. The panel is unbalanced, which means that the number of firms is not fixed and changes over time. This number ranges from 54 to 114 , and the median is 85 . Table 1 shows that the industry with the largest number of firms is Crude Petroleum and Natural Gas (SIC code 1311). Further, we observe that the level of market capitalization is widely dispersed across industries. Petroleum Refining (SIC code 2911) registers the highest value. A high book-to-market ratio means that market value is low with respect to book value; this is commonly interpreted as stocks being undervalued. The mean is quite large for industries such as Crude Petroleum and Natural Gas, Drilling Oil and Gas Wells, Oil and Gas Field Exploration Services and Petroleum Refining; however, the median is consistently below 0.6 for different industries. The standard deviation of the book-to-market ratio for these industries is consistently high. The last column of Table 1 shows descriptive statistics for raw returns. The mean and median tend to be positive for all industries except Miscellaneous Products of Petroleum and Coal (SIC code 2990). The raw returns are higher for Oil and Gas Field Machinery and Equipment (SIC code 3533), with a monthly average of $1.72 \%$, while the standard deviation of Petroleum Refining's raw returns is the lowest in the sample.

Finally, we address the most extreme observations, replacing the observations in the 1st and 99th percentiles with the values of the respective percentiles. Winsorizing ensures that extreme outliers do not drive the results. This method is currently used in cross-sectional regressions (see, for example, Ang et al 2006; Knez and Ready 1997). Further, it is particularly useful for the book-to-market observations because

${ }^{4}$ To compute oil firm returns, we obtain firm-level equity prices from the CRSP database and eliminate observations with negative asset values. 


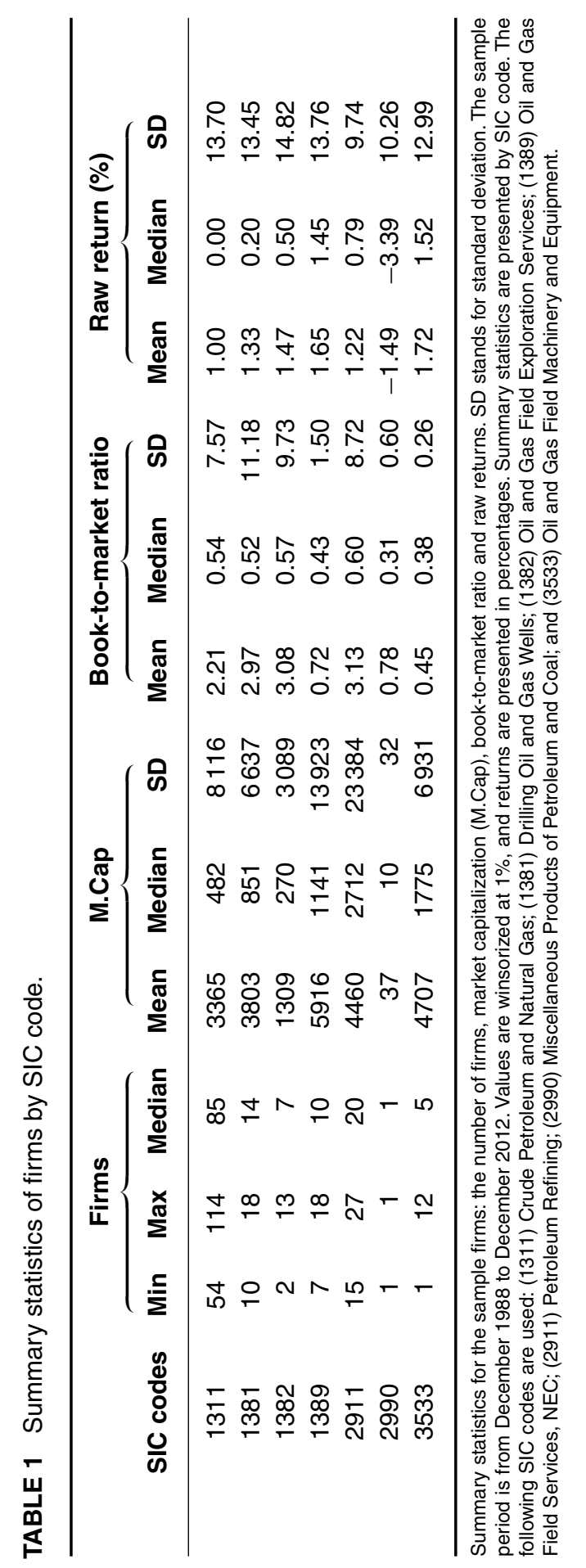


extremely large book-to-market values are sometimes observed as a result of low prices, especially before a firm delists. ${ }^{5}$

\subsection{Returns of portfolios sorted on oil price risk}

This section analyzes the performance of oil-sorted portfolios: that is to say, portfolios formed on the oil factor loading. If commodity price risk is a priced factor, then we should observe a relation between oil exposure and returns of portfolios ranked based on oil loading. ${ }^{6}$

Price commodity risk is proxied by the sensitivity (loadings) to the logarithmic change in oil prices. We estimate loadings on oil changes $\left(\beta_{\mathrm{OIL}}\right)$ for each firm corresponding to the end of each month $t$ using the following equation:

$$
R_{i t}=\alpha_{i}+\beta_{\mathrm{OIL}} R_{\mathrm{OIL}, t}+\varepsilon_{i t},
$$

where $R_{i t}$ is the excess return of stock $i$ at time $t$, and $R_{\mathrm{OIL}, t}$ is the oil return at time $t$. Oil prices are obtained from the settlement price of the New York Mercantile Exchange (NYMEX) oil futures contract (continuous price series), the most widely traded futures contract on oil drawn from Datastream. ${ }^{7}$ The estimation is conducted using a thirty-six-month rolling-window regression (see Blitz et al (2011), Lin and Zhang (2013) and Polk et al (2006) for a similar window size).

Next, five portfolios are constructed and firms are allocated to one of the five portfolios based on their $\beta_{\text {OIL }}$. We compute value-weighted and equally weighted portfolios' excess returns at $t+1 .{ }^{8}$ We repeat the estimation for every time $t$. As a result of this estimation procedure, we obtain a time series of monthly excess returns for the five portfolios.

Table 2 reports the average monthly excess returns of portfolios formed from onedimensional sorts of stocks on $\beta_{\mathrm{OIL}}$. A rolling regression is used over the period January 1992 through December 2012 (246 months). Part (a) shows the results for the value-weighted portfolio, while part (b) reports results for the equally weighted portfolio. For the value-weighted portfolio, we observe that the average return is

\footnotetext{
${ }^{5}$ Knez and Ready (1997) show that the size effect is driven by the extreme $1 \%$ of observations; when they trim this extreme $1 \%$ of observations, the coefficient for firm size changes sign.

${ }^{6} \mathrm{~A}$ limitation of this approach is that it does not control for the influence of other variables; however, it does provide preliminary evidence for the reasonability of our hypothesis.

${ }^{7}$ The futures continuous prices are a perpetual series of futures prices derived from individual futures contracts. The series begins in the nearest contract month, which forms the initial values for the continuous series until the contract reaches its expiry date. At this point, data from the next contract month is used.

${ }^{8}$ Fama and French (2008) caution against drawing strong conclusions from the spreads in equally weighted portfolio returns, as they are likely to be heavily influenced by micro stocks.
} 
TABLE 2 Portfolio sorted on oil return sensitivity.

(a) Value-weighted portfolios

\begin{tabular}{lccccccc}
\hline Quintile & $\mathbf{2 0}$ (Low) & $\mathbf{4 0}$ & $\mathbf{6 0}$ & $\mathbf{8 0}$ & $\mathbf{1 0 0}$ (High) & High-Low & $\boldsymbol{t}$-stat \\
\hline Return & 1.192 & 0.999 & 1.306 & 1.411 & 1.981 & 0.789 & 1.110 \\
$\beta_{\text {OIL }}$ & -0.003 & 0.258 & 0.397 & 0.533 & 0.786 & & \\
\hline
\end{tabular}

(b) Equally weighted portfolios

\begin{tabular}{lccccccc}
\hline Quintile & $\mathbf{2 0}$ (Low) & $\mathbf{4 0}$ & $\mathbf{6 0}$ & $\mathbf{8 0}$ & $\mathbf{1 0 0}$ (High) & High-Low & $\boldsymbol{t}$-stat \\
\hline Return & 0.834 & 1.048 & 1.319 & 1.214 & 1.599 & 0.765 & 1.070 \\
$\beta_{\text {OIL }}$ & -0.003 & 0.258 & 0.397 & 0.533 & 0.786 & & \\
\hline
\end{tabular}

(c) Averages values

\begin{tabular}{cccccc}
\hline Quintile & 20(Low) & $\mathbf{4 0}$ & $\mathbf{6 0}$ & $\mathbf{8 0}$ & 100(High) \\
\hline Market capitalization & 4669 & 8179 & 5964 & 4345 & 2273 \\
Book-to-market ratio & 3.384 & 2.684 & 2.407 & 2.018 & 1.029 \\
\hline
\end{tabular}

The excess returns of portfolios formed on $\beta_{\mathrm{OIL}}$ using (3.1). $\beta_{\mathrm{OIL}}$ are estimated using thirty-six-month rolling windows. Parts (a) and (b) report value-weighted and equally weighted portfolio returns, respectively. Returns are presented as percentages. Part (c) shows the average market capitalization and book-to-market ratio by quintiles of portfolios.

approximately $1.192 \%$ on the lowest quintile and $1.981 \%$ on the highest quintile (23.77\% annually). We further observe that portfolio returns are increasing with the oil beta, and that the spread (the difference between the average returns on the highest and lowest quintiles) is positive and equal to $0.789 \%$ (9.456\% annually). The increase in returns from the lowest quintile to the highest quintile in the equally weighted portfolio is $0.765 \%$ (9.18\% annually). Despite the economic relevance of the spreads, the difference is not statistically significant, perhaps because of the large standard deviation of oil returns. We further note that firms in the lowest oil beta quintile have negative betas (ie, they are countercyclical in relation to the oil price).

The spread between value-weighted and equally weighted portfolios tends to be positive: for the same $\beta_{\text {OIL }}$ quintile, value-weighted portfolios generally have higher returns, suggesting that large firms have higher returns. Finally, part (c) of Table 2 displays some features of the firms included in the portfolios, such as the average market capitalization and book-to-market ratio.

We observe that the book-to-market ratio is decreasing with oil loadings, and that growth-oriented firms typically have the highest $\beta_{\text {OIL }}$, while value-oriented firms have the lowest $\beta_{\text {OIL }}$. 


\section{METHODOLOGY}

In this section, we describe the methodology that we follow in this paper. The benchmark asset pricing model is given by the factor model of Fama and French (1993, 1996), which we extend by adding the momentum factor (MOM) of Carhart (1997) and an oil factor (OIL). Formally, the model is given by the following regression:

$$
R_{i t}=\alpha_{i}+\beta_{0 i} \text { market }_{t}+\beta_{1 i} \mathrm{SMB}_{t}+\beta_{2 i} \mathrm{HML}_{t}+\beta_{3 i} \mathrm{MOM}_{t}+\beta_{4 i} \mathrm{OIL}_{t}+\varepsilon_{i t},
$$

where $R_{i t}$ is the return of portfolio $i$ in excess of the risk-free rate in month $t$; market ${ }_{t}$ is the excess return on the domestic market in month $t ; \mathrm{SMB}_{t}$ (small-minus-big) is the average return on the small capitalization portfolios minus the average return on the large capitalization portfolios in month $t$; $\mathrm{HML}_{t}$ (high-minus-low) is the difference in return between a portfolio with high book-to-market ratio stocks and a portfolio with low book-to-market ratio stocks in month $t ; \mathrm{MOM}_{t}$ is the momentum factor of Carhart (1997); and $\mathrm{OIL}_{t}$ is the return on the settlement price of the NYMEX oil futures contract, the most widely traded oil futures contract. The size, value and momentum factors are obtained from Kenneth French's library (available online at http://mba.tuck.dartmouth.edu/pages/faculty/ken.french/data_library.html). ${ }^{9}$

To analyze the importance of the oil factor, we perform our analysis in two steps. First, we include the Fama-French factors in the regression equation. Second, we add the oil factor. Following Fama and French (1992), we construct twelve portfolios based on firm features, such as market capitalization, the book-to-market ratio and oil sensitivity (see the online appendix for details). We use the notation XYZ to represent one of the twelve constructed portfolios, where $\mathrm{X}$ is either $\mathrm{S}$ or $\mathrm{B}$, indicating small or large market capitalization; $\mathrm{Y}$ could be $\mathrm{H}, \mathrm{M}$ or $\mathrm{L}$, indicating high, medium or low book-to-market ratios; and $\mathrm{Z}$ is either $\mathrm{H}$ or $\mathrm{L}$, indicating high or low oil sensitivity. For example, SHH represents the average return of a portfolio with small market capitalization, a high book-to-market ratio and high oil sensitivity. The firm size in a particular year refers to the level of market capitalization at the end of June of that year, and the book-to-market ratio is calculated as the book value of common equity for the fiscal year ending in the previous calendar year divided by the market value of equity at the end of December of the previous year. ${ }^{10}$

The value-weighted monthly excess returns on these twelve portfolios are the dependent variables in time series and cross-sectional regressions. Figure 1 shows the cumulative returns of the twelve portfolios. We normalize all portfolios at 100 for

\footnotetext{
${ }^{9}$ The mimicking portfolio approach is often criticized for its creation of spurious results. The main criticism is that the features used to construct portfolios are also used to construct the factors (Lewellen et al 2010).

${ }^{10}$ Following Cohen et al (2003), we replace negative book equity values with small positive values of 1 to ensure that the book-to-market ratios are in the right tail of the distribution.
} 
FIGURE 1 Portfolios' cumulative returns.

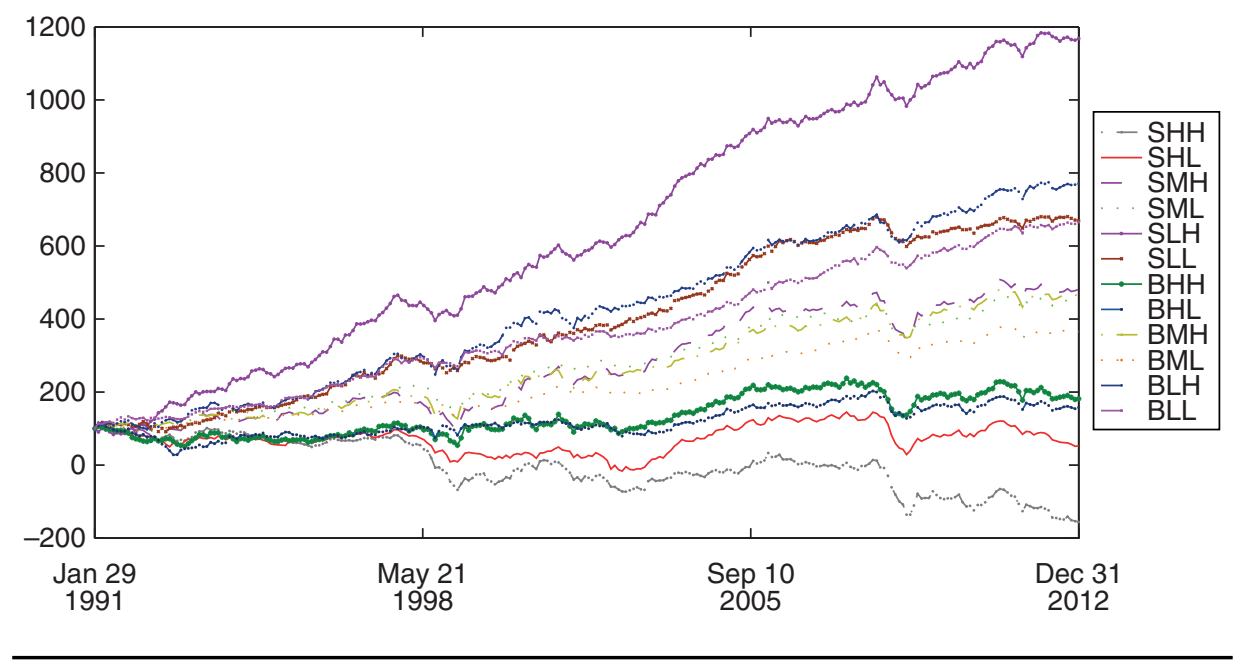

The sample period spans from January 1991 to December 2012.

the first date of the sample. The four portfolios with the best performance are SLH, BLH, SLL and BLL. These portfolios share the feature of tending toward firms with low book-to-market ratios. Certain portfolios, such as SHH, SHL and BHL, end with cumulative returns below 100, the initial value. All of these portfolios have firms with high book-to-market ratios.

Table 3 provides summary statistics for the factors. The first column corresponds to market (market), the second to size (SMB), the third to value (HML), the fourth to momentum (MOM) and the last to the oil factor (OIL). The mean of all factors is positive, with the highest being the means of the market and MOM factors, and the lowest being the mean of the value factor. Further, the oil factor shows a positive return of $0.324 \%$ ( $3.9 \%$ annually), and the standard deviation of the momentum factor is the highest among all factors.

To understand how the oil factor relates to the other factors, we compute the Pearson correlation coefficients between the factors. Table 4 reports that the market factor is positively correlated with the size and oil factors, and negatively correlated with the value and momentum factors. The oil factor is positively correlated with all factors except the momentum. The highest correlation is with the market (0.268). The momentum factor is negatively correlated with market, HML and OIL, and positively correlated with SMB. These low correlations allow us to rely on the precision of the estimation results. 
TABLE 3 Summary statistics of the factors.

\begin{tabular}{lrrrrr}
\hline & market & SMB & HML & MOM & OIL \\
\hline Mean (\%) & 0.597 & 0.265 & 0.308 & 0.525 & 0.324 \\
SD (\%) & 4.404 & 3.391 & 3.255 & 5.149 & 3.410 \\
Minimum (\%) & -17.230 & -16.390 & -12.680 & -34.720 & -9.160 \\
Median (\%) & 1.180 & 0.050 & 0.200 & 0.565 & 0.307 \\
Maximum (\%) & 11.340 & 22.020 & 13.870 & 18.390 & 13.118 \\
\hline
\end{tabular}

Summary statistics for the market and the portfolios used in time series and cross-sectional regression. "market" represents the market excess return, SMB and HML are cross-sectional factors, MOM is the momentum factor and OIL is the oil return from the NYMEX oil futures contract. Returns are presented as percentages.

TABLE 4 Correlations between factors.

\begin{tabular}{lrrrrr}
\hline & market & SMB & HML & MOM & OIL \\
\hline market & 1 & & & & \\
SMB & 0.240 & 1 & & & \\
HML & -0.249 & -0.341 & 1 & & \\
MOM & -0.251 & 0.067 & -0.139 & 1 & \\
OIL & 0.268 & 0.164 & 0.019 & -0.102 & 1 \\
\hline
\end{tabular}

Pearson correlation coefficients between the factors: market, SMB, HML, MOM and OIL. "market" represents the market excess return, SMB and HML are Fama and French factors, MOM is the momentum factor and OIL is the oil return from the NYMEX oil futures contract.

\subsection{Time series analysis}

In a factor-pricing model, the mean return increases with factor loadings, and the factor premium for a given zero-investment factor is equal to the mean return on that factor (the mean return in excess of the risk-free rate for the market factor). Consequently, the intercept term of a time series regression of a portfolio's excess returns on zero-investment or excess factor returns measures the mean abnormal return, or the return in excess of what is predicted by the factor-pricing model. Therefore, tests of factor-pricing models in this context rely on the intercepts from time series regressions to suggest how well an asset pricing model can explain the cross-section of average returns (see, for example, Fama and French 1993, 1996; Gibbons et al 1989). Intercepts that are indistinguishable from zero are consistent with rational factor pricing (Merton 1973). However, as stated in Hou et al (2012), the success of the factor-pricing model in the time series test is a necessary but insufficient condition to confirm rational risk pricing.

To evaluate the overall ability of a specific model to explain excess returns, we adopt the test proposed by Gibbons et al (1989) (hereafter, the GRS test). The null hypothesis of the GRS test assumes that all pricing errors are jointly equal to zero. 
The GRS test is largely based on a finite-sample $F$-test, presented as follows:

$$
\mathrm{GRS}=\frac{T-N-K}{N}\left[1+E_{t}\left(f_{t}\right)^{\prime} \hat{\Omega}^{-1} E_{t}\left(f_{t}\right)\right]^{-1} \hat{\alpha}^{\prime} \hat{\Sigma}^{-1} \hat{\alpha} \equiv F_{N, T-N-K},
$$

where $T$ is the number of observations across time, $N$ is the number of portfolios, $K$ is the number of factors, $f_{t}$ is the vector of factors at time $t$,

$$
\hat{\Omega}=\frac{1}{T} \sum_{t=1}^{T}\left(f_{t}-E_{T}(f)\right)\left(f_{t}-E_{T}(f)\right)^{\prime}
$$

is the covariance matrix of the factors, and

$$
\hat{\Sigma}=\frac{1}{T} \sum_{t=1}^{T} \hat{\varepsilon}_{t} \hat{\varepsilon}_{t}^{\prime}
$$

is the residual covariance matrix. The rejection of the null hypothesis indicates that at least one of the pricing errors is not zero, and, consequently, the considered pricing model is not sufficient to explain excess returns. ${ }^{11}$

\subsection{Cross-sectional analysis}

Fama and MacBeth (1973) propose a procedure to conduct cross-sectional regressions for asset returns. The two-step procedure consists of estimating the betas and the risk premium for any factor that is expected to determine asset prices. The first step estimates the betas using time series regressions, where each portfolio excess return is regressed against the proposed risk factors. The second step provides estimates of the risk premium for each factor by conducting a cross-sectional regression at each time period of all portfolio excess returns on the estimated betas from the first step. ${ }^{12}$ In particular, we estimate the following main equations for each time $t$ and

\footnotetext{
${ }^{11}$ Time series regression tests have an advantage in that the time series slopes are factor loadings with a clear interpretation. Moreover, this method can avoid the problem of error in variables because all factors are observable, whereas in the cross-sectional methodology, the regressors are the estimated betas obtained from the time series regression step. Our particular case does not involve autocorrelation, and we do not need to use the Newey-West corrected standard errors and test statistics.

${ }^{12}$ The advantages of this method are allowing betas to change over time and generating standard errors and test statistics.
} 
$i=1, \ldots, N$ :

$$
\begin{aligned}
R_{i, t}= & \hat{\beta}_{\text {market }, i} \lambda_{\text {market }, t}+\hat{\beta}_{\mathrm{SMB}, i} \lambda_{\mathrm{SMB}, t}+\hat{\beta}_{\mathrm{HML}, i} \lambda_{\mathrm{HML}, t}+\epsilon_{i, t}, \\
R_{i, t}= & \hat{\beta}_{\text {market }, i} \lambda_{\text {market }, t}+\hat{\beta}_{\mathrm{SMB}, i} \lambda_{\mathrm{SMB}, t}+\hat{\beta}_{\mathrm{HML}, i} \lambda_{\mathrm{HML}, t} \\
& \quad+\hat{\beta}_{\mathrm{MOM}, i} \lambda_{\mathrm{MOM}, i}+\epsilon_{i, t}, \\
R_{i, t}= & \hat{\beta}_{\text {market }, i} \lambda_{\text {market }, t}+\hat{\beta}_{\mathrm{SMB}, i} \lambda_{\mathrm{SMB}, t}+\hat{\beta}_{\mathrm{HML}, i} \lambda_{\mathrm{HML}, t} \\
& \quad+\hat{\beta}_{\mathrm{MOM}, i} \lambda_{\mathrm{MOM}, i}+\hat{\beta}_{\mathrm{OIL}} \lambda_{\mathrm{OIL}, t}+\epsilon_{i, t},
\end{aligned}
$$

where $\hat{\beta}_{\text {market }, i}, \hat{\beta}_{\mathrm{SMB}, i}, \hat{\beta}_{\mathrm{HML}, i}, \hat{\beta}_{\mathrm{MOM}, i}$ and $\hat{\beta}_{\mathrm{OIL}, t}$ are the factor loadings obtained from the time series regression. Equation (4.2) is our benchmark model, and (4.4) allows us to test whether oil is a priced factor in the presence of Fama-French factors and momentum.

The factor risk premiums $(\lambda)$ and pricing errors $(\epsilon)$ of (4.2)-(4.4) are estimated as the average of the cross-sectional estimates

$$
\hat{\lambda}=\frac{1}{T} \sum_{t=1}^{T} \hat{\lambda}_{t} \quad \text { and } \quad \hat{\epsilon}_{i}=\frac{1}{T} \sum_{t=1}^{T} \hat{\epsilon}_{t},
$$

with the following variances:

$$
\hat{\sigma}_{\lambda}^{2}=\frac{1}{T^{2}} \sum_{t=1}^{T}\left(\hat{\lambda}_{t}-\hat{\lambda}\right)^{2} \quad \text { and } \quad \hat{\sigma}_{\epsilon_{i}}^{2}=\frac{1}{T^{2}} \sum_{t=1}^{T}\left(\hat{\epsilon}_{t}-\hat{\epsilon}_{i}\right)^{2},
$$

respectively. If the estimated betas are important determinants of average returns, then the risk premiums in (4.2)-(4.4) should be statistically significant.

The Fama-MacBeth standard errors presented in (4.6) do not account for the fact that $\beta$ are estimated. Therefore, we use the Shanken (1992) correction to obtain the correct asymptotic standard errors of the vector of factor risk premiums. This is calculated as follows:

$$
\hat{\sigma}_{\lambda \text { shanken }}^{2}=T^{-1}\left(1+\hat{\lambda} \hat{\Omega}^{-1} \hat{\lambda}\right)\left[T \hat{\sigma}_{\lambda}^{2}-\hat{\Omega}\right]+T^{-1} \hat{\Omega},
$$

where, as before, $\hat{\Omega}$ is the $K \times K$ covariance matrix of the factors.

\section{EMPIRICAL RESULTS}

In this section, we report the empirical results of the time series and cross-sectional analyses. In Section 5.1, we conduct tests to examine the ability of common factors to explain the time series and the cross-section of returns of firms in the oil and natural gas industry. In Section 5.2, we examine the importance of the oil factor in deriving the returns of oil-dependent firms after we control for common factors. 


\subsection{Testing the traditional asset pricing models}

\subsubsection{Time series regressions}

Table 5 presents the results of the time series estimation of (4.1) using only Fama and French factors: market, SMB and HML. The dependent variables are the returns on the twelve portfolios that are formed based on the firm features of size, book-tomarket ratio and oil sensitivity. Part (a) presents the results for portfolios with low oil beta sensitivity, and part (b) shows the results for portfolios with high oil beta sensitivity. Further, the first four columns present the estimates of the coefficients in (4.1) (below, we present the corresponding $t$-statistics) and the last column shows the $R^{2}$ of the estimation.

We find that the coefficient estimates of the market factor are always positive and statistically significant. Moreover, the portfolios with high loading on the oil factor have a high market coefficient. Regarding the size factor (SMB), its coefficient estimates are generally positive for portfolios of small firms but not statistically significant for portfolios of large firms. This result indicates that the factor SMB explains the returns of portfolios of small firms. Turning to the value factor (HML), its coefficient estimates are positive and statistically significant for all twelve portfolios. $R^{2}$ indicates that the three factors explain between $22.9 \%$ and $45.5 \%$ of the variation in the returns of the twelve portfolios. Finally, the GRS test rejects the null hypothesis that all pricing errors are equal to zero, which might indicate that another factor (or factors) is (are) missing.

Table 6 reports the results of the time series estimation of the four-factor model that includes the momentum factor (MOM), in addition to the three factors above (market, SMB, HML). Including the momentum factor does not alter the previous conclusions; we generally find similar results for the sign and statistical significance of the coefficient estimates of the market, SMB and HML factors. We further find a similar pattern concerning the magnitude of the coefficient estimates with respect to low and high oil beta sensitivity and book-to-market ratios. Regarding the coefficient estimate for the momentum factor, its sign is generally positive for firms with low oil coefficients, and inconclusive for those with high oil coefficients. The momentum factor tends to be statistically insignificant except for portfolios of small firms. ${ }^{13}$

\footnotetext{
${ }^{13}$ While the small firm risk premiums can be easily attributed to a higher small firm rate of failure, and the value premiums can be seen as compensation for investing in distressed firms, the interpretation of the risk premium of the momentum factor has been the subject of much discussion. Jegadeesh and Titman (1993) have posited a behavioral explanation, which interprets momentum profits as behavioral underreaction to firm-specific information; this has been widely followed in the literature. For instance, Barberis et al (1998), Hong and Stein (1999) and Jegadeesh and Titman (2001) have attempted to explain the underreaction-related empirical patterns by relying on a variety of psychological biases, such as conservatism, self-attributive overconfidence and slow information
} 
TABLE 5 Time series regressions for the three-factor model.

\begin{tabular}{|c|c|c|c|c|c|c|c|c|c|}
\hline \multirow{3}{*}{$\begin{array}{l}\text { Size, } \\
\text { BTM } \\
\text { ratio }\end{array}$} & \multicolumn{8}{|c|}{ (a) Low $\beta_{\text {OIL }}$} & \multirow[b]{3}{*}{$R^{2}$} \\
\hline & \multicolumn{4}{|c|}{ Estimates } & \multicolumn{4}{|c|}{$t$-statistic } & \\
\hline & alpha & market & SMB & HML & alpha & market & SMB & HML & \\
\hline SHL & -1.127 & 1.002 & 0.535 & 0.823 & -3.277 & 12.510 & 4.991 & 7.358 & 0.455 \\
\hline SML & 0.522 & 0.793 & 0.550 & 0.530 & 1.332 & 8.694 & 4.507 & 4.155 & 0.303 \\
\hline SLL & 1.476 & 0.715 & 0.566 & 0.362 & 3.600 & 7.485 & 4.430 & 2.712 & 0.257 \\
\hline $\mathrm{BHL}$ & -0.530 & 0.956 & 0.151 & 0.491 & -1.622 & 12.556 & 1.480 & 4.610 & 0.399 \\
\hline BML & 0.279 & 0.906 & 0.018 & 0.560 & 0.878 & 12.255 & 0.185 & 5.423 & 0.384 \\
\hline BLL & 1.514 & 0.838 & -0.002 & 0.432 & 4.270 & 10.143 & -0.017 & 3.746 & 0.293 \\
\hline
\end{tabular}

(b) High $\beta_{\text {OIL }}$

\begin{tabular}{|c|c|c|c|c|c|c|c|c|c|}
\hline \multirow{2}{*}{$\begin{array}{l}\text { Size, } \\
\text { BTM } \\
\text { ratio }\end{array}$} & \multicolumn{4}{|c|}{ Estimates } & \multicolumn{4}{|c|}{$t$-statistic } & \multirow[b]{2}{*}{$R^{2}$} \\
\hline & alpha & market & SMB & HML & alpha & market & SMB & HML & \\
\hline $\mathrm{SHH}$ & -2.010 & 0.992 & 0.669 & 0.877 & -4.440 & 9.411 & 4.742 & 5.959 & 0.342 \\
\hline SMH & 0.283 & 1.250 & 0.546 & 0.864 & 0.543 & 10.286 & 3.360 & 5.091 & 0.342 \\
\hline SLH & 2.991 & 0.908 & 0.700 & 0.895 & 5.234 & 6.821 & 3.933 & 4.815 & 0.229 \\
\hline $\mathrm{BHH}$ & -0.552 & 1.108 & 0.200 & 0.486 & -1.313 & 11.315 & 1.526 & 3.549 & 0.351 \\
\hline $\mathrm{BMH}$ & 0.420 & 1.157 & 0.246 & 0.629 & 0.863 & 10.209 & 1.620 & 3.969 & 0.310 \\
\hline BLH & 1.739 & 1.006 & 0.266 & 0.365 & 3.520 & 8.746 & 1.726 & 2.270 & 0.252 \\
\hline ( & .00 & & & & & & & & \\
\hline
\end{tabular}

The coefficient estimates and corresponding $t$-statistics of the factor model in (4.1). The factors are market, SMB and HML. "market" represents the market excess return, and SMB and HML are Fama and French factors. The dependent variables are the returns on twelve portfolios sorted by market capitalization (size), book-to-market (BTM) ratio and oil sensitivity. The $R^{2}$ values from each time series are reported after the $t$-statistics. The last row reports the adjusted $p$-value from the GRS test.

Finally, $R^{2}$ ranges from $22.9 \%$ to $46.5 \%$; thus, controlling for the MOM factor leads to a negligible improvement in explaining the time variation of portfolio returns. The GRS test still rejects the null hypothesis that all pricing errors are equal to zero. This

diffusion. According to this explanation, security prices underreact to news, which is incorporated slowly into prices, yielding price momentum. However, other authors postulate a risk explanation. Chordia and Shivakumar (2006) argue that momentum profits can be explained by business cycles, while Liu and Zhang (2008) argue that it is macroeconomic risk, more specifically the growth rate of industrial production, that explains the momentum factor. 
result may again indicate that the four-factor model is misspecified, and that other factors might therefore be relevant.

\subsubsection{Cross-sectional regressions}

We use the betas estimated in the previous section to examine if the factors (market, SMB, HML and MOM) are priced on the cross-section of returns of firms in the oil industry. Before estimating the final regression, we conduct a preliminary analysis to investigate the correlations between risk premiums $\lambda$. Examining these correlations should help us detect redundant information among the traditional factors that can harm the statistical significance of certain (or all) risk premiums. Thus, if information redundancy is present, we remove the corresponding betas from our final regressions.

Table 7 reports the results of the calculation of correlations. This table shows that $\lambda_{\text {market }}$ and $\lambda_{\mathrm{HML}}$ are highly correlated. Further, using regression analysis, we find that the sign of $\lambda_{\text {market }}$ becomes negative when we estimate a factor model that includes the coefficient of the HML factor as a regressor. Together, these two results suggest that $\lambda_{\text {HML }}$ causes multicollinearity. To prevent this from affecting the statistical significance of other risk premiums, we remove the HML factor from our final cross-sectional regressions. We obtain robust results in concordance with the previous estimations in terms of sign and statistical significance.

Table 8 reports the final estimation results for the two-factor (part (a)) and threefactor (part (b)) models. We observe that all risk premium estimates are positive. Therefore, returns depend positively on market, SMB and MOM factors in accordance with the findings of the literature. When we examine the reported adjusted $t$-statistics, we observe that all factors are statistically significant at conventional significance levels, except for $\lambda_{\text {market }}$ in the three-factor model, which is statistically significant only at the $10 \%$ level. Regarding the results of the test of mispricing, a $p$-value of 0.000 for the two-factor model reveals mispricing in the cross-section of the benchmark model. However, the inclusion of the momentum factor changes our conclusions. Contrary to the results obtained for the time series analysis, the momentum factor appears to be a crucial factor driving the cross-section of prices in oil and natural gas firms.

\subsection{The asset pricing model extended with an oil factor}

In this section, we re-estimate the previous time series and cross-sectional regressions after including the oil factor. We begin with a discussion of the time series regression results. This is followed by an analysis of the cross-sectional regression results. 

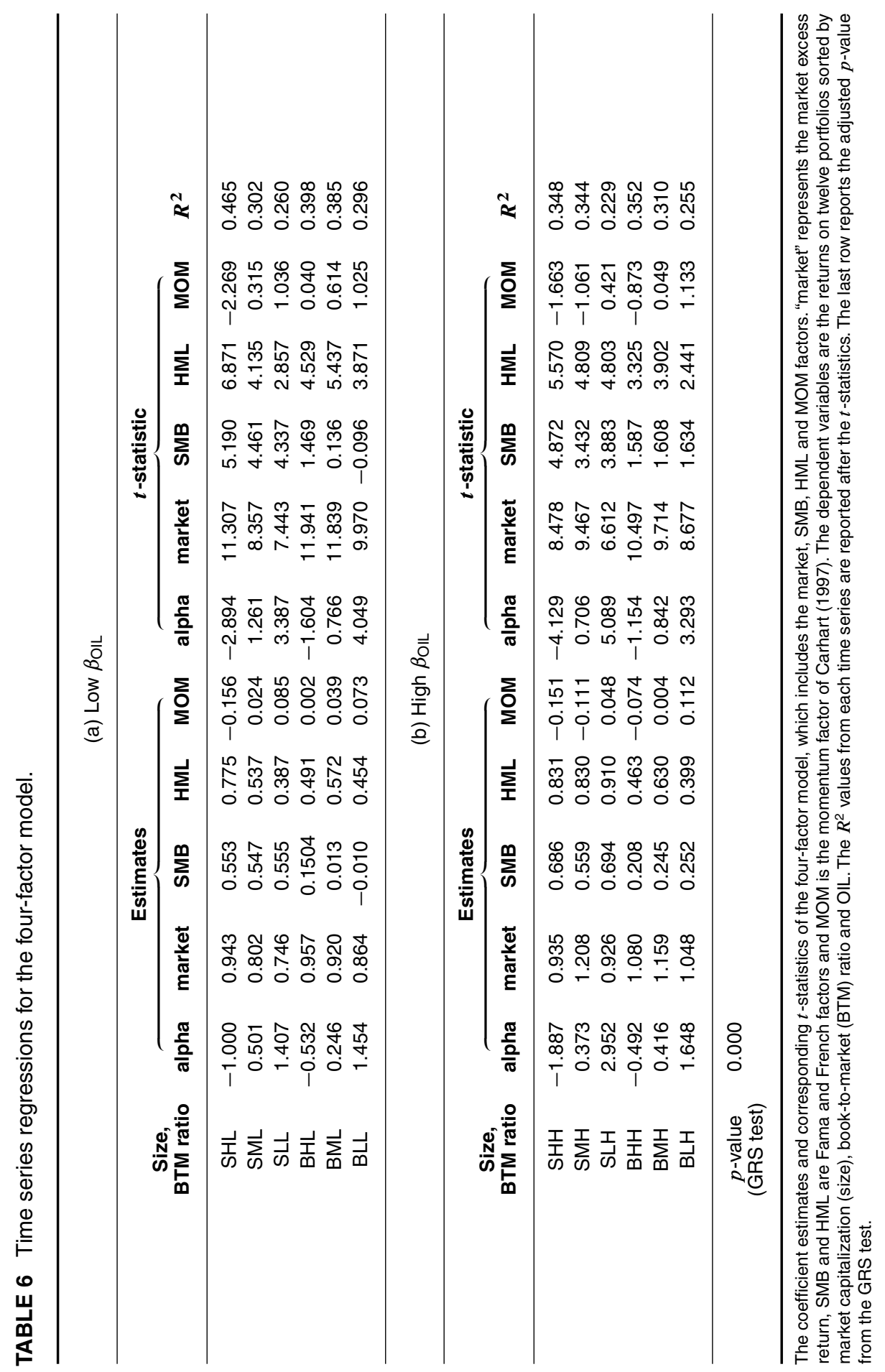
TABLE 7 Correlation of risk premiums $(\lambda)$.

\begin{tabular}{llrrrr}
\hline & $\lambda_{\text {market }}$ & $\lambda_{\text {SMB }}$ & $\lambda_{\text {HML }}$ & $\lambda_{\text {MOM }}$ \\
\hline$\lambda_{\text {market }}$ & 1.000 & 0.252 & -0.627 & -0.219 \\
$\lambda_{\text {SMB }}$ & 0.250 & 1.000 & -0.401 & 0.076 \\
$\lambda_{\text {HML }}$ & -0.627 & -0.401 & 1.000 & 0.454 \\
$\lambda_{\text {MOM }}$ & -0.219 & 0.076 & 0.454 & 1.000 \\
\hline
\end{tabular}

The correlation coefficients between the four risk premiums: $\lambda_{\text {market }}, \lambda_{\mathrm{SMB}}, \lambda_{\mathrm{HML}}$ and $\lambda_{\mathrm{MOM}}$. See (4.4).

TABLE 8 Cross-sectional regressions: two- and three-factor models.

(a) Two-factor model

\begin{tabular}{lcccc}
\hline & Estimate & $\begin{array}{c}\text { Standard } \\
\boldsymbol{t} \text {-stat }\end{array}$ & $\begin{array}{c}\text { Adjusted } \\
\boldsymbol{t} \text {-stat }\end{array}$ & $\begin{array}{c}\text { Adjusted } \\
\boldsymbol{p} \text {-value }\end{array}$ \\
\hline$\lambda_{\text {market }}$ & 1.112 & 2.404 & 2.299 & 0.000 \\
$\lambda_{\mathrm{SMB}}$ & 1.169 & 2.452 & 2.322 & \\
\hline
\end{tabular}

(b) Three-factor model

\begin{tabular}{lrrrc}
\hline & Estimate & $\begin{array}{c}\text { Standard } \\
\boldsymbol{t} \text {-stat }\end{array}$ & $\begin{array}{c}\text { Adjusted } \\
\boldsymbol{t} \text {-stat }\end{array}$ & $\begin{array}{c}\text { Adjusted } \\
\boldsymbol{p} \text {-value }\end{array}$ \\
\hline$\lambda_{\text {market }}$ & 1.839 & 3.844 & 1.779 & 0.088 \\
$\lambda_{\mathrm{SMB}}$ & 2.519 & 5.170 & 2.219 & \\
$\lambda_{\text {MOM }}$ & 10.855 & 12.161 & 5.073 & \\
\hline
\end{tabular}

The coefficient estimates of the second-stage cross-sectional regression results for the (a) two-factor model and (b) three-factor model. The sample means of monthly portfolio excess returns are regressed on the betas without the intercept. Individual $t$-statistics and $p$-values are reported next to the coefficient estimates. Adjusted $t$-statistics and adjusted $p$-values for the significance of mispricing errors are reported based on the Shanken (1992) correction.

\subsubsection{Time series regressions}

The results for the five-factor model that adds OIL to the classical factors (market, SMB, HML and MOM) are presented in Table 9. First, we observe that the estimates of the market coefficients remain positive and statistically significant after the inclusion of OIL. However, the magnitude of its effect decreases compared with the results presented in Table 6. Second, the estimates of the coefficients of the SMB factor are positive for small firms and negative for large firms, and they are statistically significant only for the portfolios of small firms. Third, the estimates of the HML coefficients remain positive and generally statistically significant in the presence of the oil factor, but for the market and SMB factors, the magnitude of the effect decreases. Finally, we still find that the sign of the coefficient estimate of MOM is generally 
positive for low oil betas and inconclusive for high oil betas. This factor is, again, statistically insignificant, except for the result for small firms.

Interestingly, the estimates of the coefficients of the new factor OIL are positive and highly statistically significant. Further, the magnitude of its effect increases with the oil beta. The comparison of the $R^{2}$ of the regressions reported in Tables 6 and 9 clearly show that adding the oil factor substantially increases the explanatory power of the model. In the absence of OIL, the $R^{2}$ ranges from $22.9 \%$ to $46.5 \%$, whereas it increases to $30.9 \%$ and $72.6 \%$ with OIL included. The increase in $R^{2}$ is substantially larger for high oil loadings portfolios (ie, for the portfolios with high commodity price risk). Finally, in the benchmark model, the GRS test does reject the null hypothesis that all pricing errors are equal to zero; therefore, the extended model might still contain some specification errors. However, including the oil factor substantially increases the explanatory power of the model.

\subsubsection{Cross-sectional regressions}

Table 10 displays the results of the second step of the two-step procedure of Fama and MacBeth (1973) for estimating the five-factor model in (4.4) after we exclude the HML factor. The latter model includes OIL as a main factor. The exclusion of the HML factor is based on the results obtained in Section 5.1.2.

As we found in Table 8, the risk premiums of the market, SMB and MOM factors are positive, and SMB and MOM are statistically significant. Interestingly, the risk premium of the oil factor is positive and highly statistically significant. This result indicates that OIL is a priced factor for the oil industry. Finally, the adjusted $p$-value of 0.041 for the statistical significance of pricing errors indicates that there is no mispricing in the cross-section of the above four-factor model at a $1 \%$ significance level.

Overall, the results suggest the statistical significance of not only the oil factor but also the size and momentum factors.

\section{ROBUSTNESS}

In this section, we recheck the importance of the oil factor for the cross-section of stock returns in oil-dependent industries by controlling for additional known risk factors. The literature on this topic is quite vast. ${ }^{14}$ We use factors such as the profitability factor (Novy-Marx 2013), the liquidity factor of Pastor and Stambaugh (2003) and a term structure factor (Fama and French 1993). The profitability factor introduced in Novy-Marx (2013) is a quality metric that measures the relation of gross profits to assets. The liquidity factor of Pastor and Stambaugh (2003) is defined as an innovation

\footnotetext{
${ }^{14}$ Harvey et al (2016) survey more than 200 factors.
} 


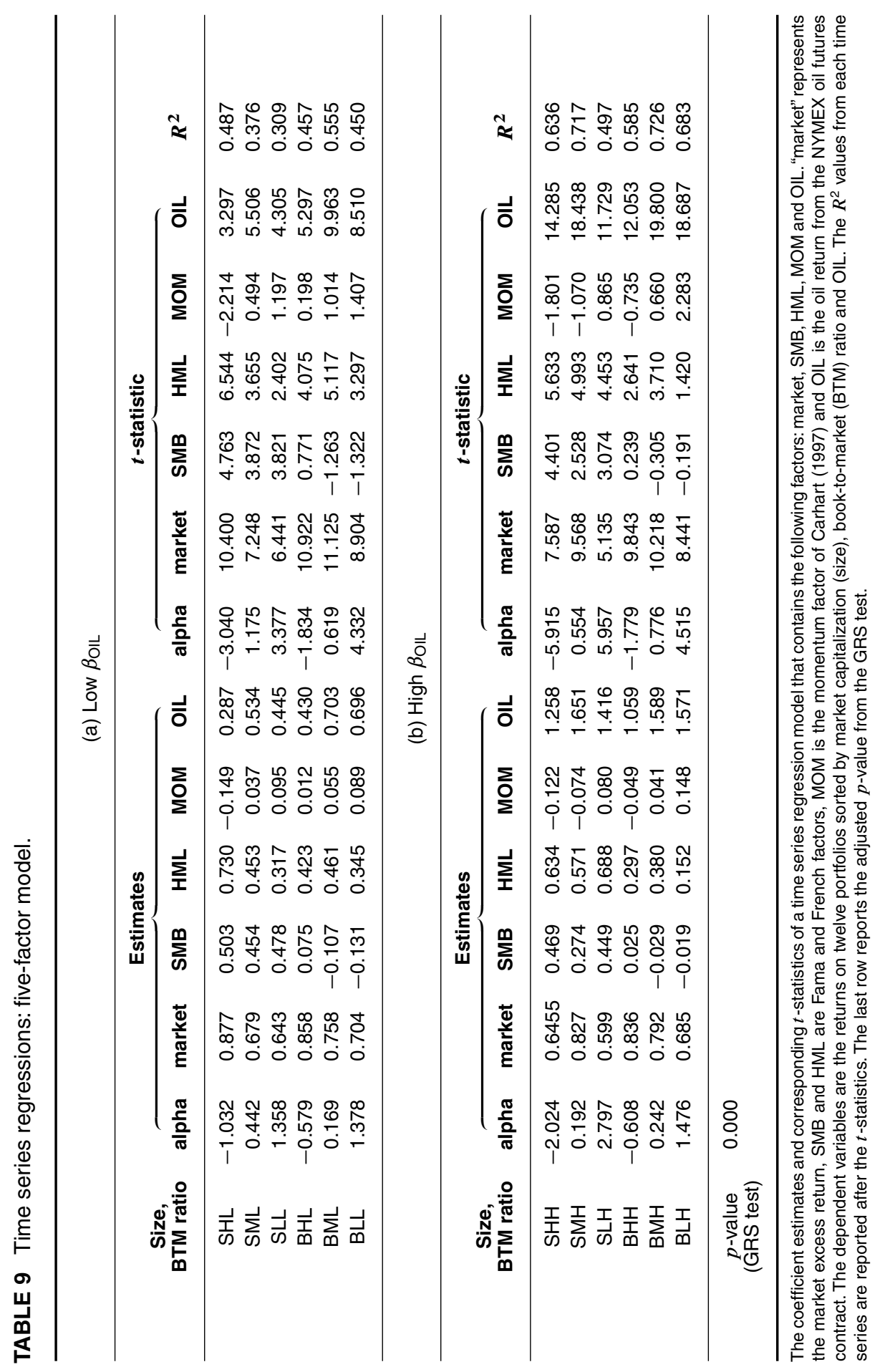


TABLE 10 Estimation of risk premiums: four-factor model.

\begin{tabular}{lrrrc}
\hline & Estimate & $\begin{array}{c}\text { Standard } \\
\boldsymbol{t} \text {-stat }\end{array}$ & $\begin{array}{c}\text { Adjusted } \\
\boldsymbol{t} \text {-stat }\end{array}$ & $\begin{array}{c}\text { Adjusted } \\
\boldsymbol{p} \text {-value }\end{array}$ \\
\hline$\lambda_{\text {market }}$ & 0.845 & 1.891 & 0.941 & 0.041 \\
$\lambda_{\mathrm{SMB}}$ & 2.196 & 4.520 & 2.033 & \\
$\lambda_{\mathrm{MOM}}$ & 10.622 & 11.964 & 5.234 & \\
$\lambda_{\mathrm{OIL}}$ & 0.902 & 3.466 & 2.800 & \\
\hline
\end{tabular}

The coefficient estimates of the second-stage cross-sectional regression results for the four-factor model that includes the oil factor. The sample means of monthly portfolio excess returns are regressed on the betas without the intercept. Individual $t$-statistics and $p$-values are reported next to the coefficient estimates. Adjusted $t$-statistics and adjusted $p$-values for the significance of mispricing errors are reported based on the Shanken (1992) correction.

TABLE 11 Correlation of risk premiums.

\begin{tabular}{lrrrrrrr}
\hline & $\lambda_{\text {market }}$ & $\lambda_{\text {SMB }}$ & $\lambda_{\text {OIL }}$ & $\lambda_{\text {MOM }}$ & $\lambda_{\text {profit }}$ & $\lambda_{\text {liquidity }}$ & $\lambda_{\text {term }}$ \\
\hline$\lambda_{\text {market }}$ & 1.000 & 0.541 & 0.153 & 0.065 & 0.671 & 0.225 & 0.192 \\
$\lambda_{\text {SMB }}$ & 0.541 & 1.000 & 0.178 & 0.267 & 0.612 & 0.394 & 0.255 \\
$\lambda_{\text {OIL }}$ & 0.153 & 0.178 & 1.000 & 0.083 & 0.045 & 0.092 & 0.129 \\
$\lambda_{\text {MOM }}$ & 0.065 & 0.267 & 0.083 & 1.000 & 0.266 & -0.044 & 0.577 \\
$\lambda_{\text {profit }}$ & 0.671 & 0.612 & 0.045 & 0.266 & 1.000 & 0.378 & 0.535 \\
$\lambda_{\text {liquidity }}$ & 0.225 & 0.394 & 0.092 & -0.044 & 0.378 & 1.000 & -0.227 \\
$\lambda_{\text {term }}$ & 0.192 & 0.255 & 0.129 & 0.577 & 0.535 & -0.227 & 1.000 \\
\hline
\end{tabular}

The correlation coefficients between the eight risk premiums: $\lambda_{\text {market }}, \lambda_{\mathrm{SMB}}, \lambda_{\mathrm{HML}}, \lambda_{\mathrm{OIL}}, \lambda_{\mathrm{MOM}}, \lambda_{\text {profit }}, \lambda_{\text {liquidity }}$ and $\lambda_{\text {term. }}$.

in the aggregate liquidity. The term structure factor is related to unexpected changes in the return on long-term government bonds. This factor is computed as a monthly change in the ten-year treasury constant maturity yield using data obtained from the Board of Governors of the Federal Reserve System (Fama and French 1993).

The estimation results of the above factor model are presented in Table 12. Before discussing the new results, we note that, as in Section 5.1.2, we begin by computing the correlation matrix of the vector of risk premiums $\lambda$ (see Table 11). In this table, we observe a high correlation between $\lambda_{\text {market }}$ and $\lambda_{\text {profit }}, \lambda_{\text {SMB }}$ and $\lambda_{\text {profit }}$, and $\lambda_{\text {MOM }}$ and $\lambda_{\text {term }}$. Moreover, regression analysis results show that the signs of $\lambda_{\text {market }}, \lambda_{\mathrm{SMB}}, \lambda_{\mathrm{MOM}}$, $\lambda_{\text {profit }}$ and $\lambda_{\text {term }}$ change when we include or exclude certain factors in the regressions, given the high correlations between some of these factors. Thus, to obtain our final results for the estimation of cross-sectional regressions, we remove the betas for some factors from our final cross-sectional regressions in some cases.

The estimation results using the profitability factor are reported in part (a) of Table 12 . The results show that this factor has a negative and statistically significant 
effect. The MOM and oil factors remain statistically significant, although the latter is significant at the $10 \%$ significance level. Further, we test for the importance of the oil factor in the presence of a liquidity factor. Following Pastor and Stambaugh (2003), instead of considering the level of liquidity as a relevant asset pricing factor, we use innovations in aggregate liquidity, because the effects of these innovations are pervasive across common stocks (see also Chordia et al $(2000,2001)$ for a similar measure of liquidity). Pastor and Stambaugh (2003) argue that the liquidity risk factor can account for a large portion of momentum profits. Part (b) of Table 12 shows that the coefficient of the liquidity factor is not statistically significant, although the coefficients of MOM and OIL remain highly significant. Finally, we test the importance of the oil factor in the presence of the term structure factor. The results in part (c) of Table 12 show that the SMB, oil and term factors are statistically significant. However, unlike in the presence of the profitability factor or liquidity factor, the null hypothesis of no mispricing errors is rejected at all conventional significance levels. This indicates that the model may be misspecified.

\section{CONCLUSION}

A recent strand of literature has addressed the question of how industry features can impact asset pricing. Several works suggest that standard asset pricing models fail to explain the cross-section of returns of industry portfolios (Chou et al 2012; Lewellen et al 2010), and that other factors are needed to price firms in industries (Baek and Bilson 2015; Viale et al 2009; Zeng et al 2014).

This paper analyzes the case of commodity-dependent industries. Commodity dependence creates a strong link between the price of the commodity, firm profitability and investment decisions and expected returns; thus, we posit that investors might price this risk. We test in the case of the oil industry and analyze whether oil exposure relates to the cross-section of returns.

We follow the previous asset pricing approaches and construct portfolios that are sorted on the oil exposure. We find that the value-weighted portfolio annualized returns for firms in the lowest oil factor loading decile have a monthly average equal to $0.0788 \%$, whereas value-weighted returns for firms in the highest oil loading decile have a monthly average greater than or equal to $0.765 \%$. These findings are particularly relevant for constructing portfolios exposed to oil price risk. The annual return of an investment strategy that is long on high oil sensitivity and short on low oil sensitivity yields $9.45 \%$, on an annual basis, for an equally weighted portfolio, and 9.18\%. This guides investors to construct portfolios that explore the return differential.

In the cross-sectional regression, we use the Fama-French factor model expanded to include momentum and oil factors. The empirical results show that the oil factor performs well in both time series and cross-sectional analyses. The cross-sectional 
TABLE 12 Alternative specifications of cross-sectional regressions.

(a) Three-factor model + profitability factor

\begin{tabular}{lrrrc}
\hline & Estimate & $\begin{array}{c}\text { Standard } \\
\boldsymbol{t} \text {-stat }\end{array}$ & $\begin{array}{c}\text { Adjusted } \\
\boldsymbol{t} \text {-stat }\end{array}$ & $\begin{array}{c}\text { Adjusted } \\
\boldsymbol{p} \text {-value }\end{array}$ \\
\hline$\lambda_{\mathrm{SMB}}$ & 0.035 & 0.069 & 0.026 & 0.246 \\
$\lambda_{\text {MOM }}$ & 11.040 & 12.128 & 4.427 & \\
$\lambda_{\mathrm{OIL}}$ & 0.657 & 2.490 & 1.769 & \\
$\lambda_{\text {profit }}$ & -0.035 & -7.419 & -2.666 & \\
\hline
\end{tabular}

(b) Four-factor model + liquidity factor

\begin{tabular}{lrrrc}
\hline & Estimate & $\begin{array}{c}\text { Standard } \\
\boldsymbol{t} \text {-stat }\end{array}$ & $\begin{array}{c}\text { Adjusted } \\
\boldsymbol{t} \text {-stat }\end{array}$ & $\begin{array}{c}\text { Adjusted } \\
\boldsymbol{p} \text {-value }\end{array}$ \\
\hline$\lambda_{\text {market }}$ & 0.173 & 0.347 & 0.151 & 0.074 \\
$\lambda_{\mathrm{SMB}}$ & 1.990 & 4.214 & 1.734 & \\
$\lambda_{\mathrm{MOM}}$ & 11.509 & 12.258 & 4.838 & \\
$\lambda_{\mathrm{OIL}}$ & 0.851 & 3.302 & 2.661 & \\
$\lambda_{\text {liquidity }}$ & 0.005 & 2.747 & 1.055 & \\
\hline
\end{tabular}

(c) Three-factor model + term structure factor

\begin{tabular}{lrrrc}
\hline & Estimate & $\begin{array}{c}\text { Standard } \\
\boldsymbol{t} \text {-stat }\end{array}$ & $\begin{array}{c}\text { Adjusted } \\
\boldsymbol{t} \text {-stat }\end{array}$ & $\begin{array}{c}\text { Adjusted } \\
\boldsymbol{p} \text {-value }\end{array}$ \\
\hline$\lambda_{\mathrm{SMB}}$ & 1.862 & 3.938 & 2.599 & 0.000 \\
$\lambda_{\mathrm{OIL}}$ & 1.444 & 5.162 & 4.408 & \\
$\lambda_{\text {term }}$ & -0.271 & -4.788 & -3.047 & \\
\hline
\end{tabular}

The coefficient estimates of the second-stage cross-sectional regression results for several factor models. The sample means of monthly portfolio excess returns are regressed on the betas without the intercept. Individual $t$ statistics and $p$-values are reported next to the coefficient estimates. Adjusted $t$-statistics and adjusted $p$-values for the significance of mispricing errors are reported based on the Shanken (1992) correction.

regression confirms that the oil factor is a key factor that helps to explain average return in the oil industry. Other factors such as size and momentum further provide a risk premium.

Our asset pricing analysis results have a number of useful insights for investors and policy makers. Oil and natural gas companies are among the largest market capitalization companies in the world. Therefore, it is important that investors and regulators assess the correct risk profile of these firms and understand the pricing process of such firms. Our results suggest that oil price exposure should be accounted for, while market risk does not seem to imply risk compensation. These results are 
helpful in determining the correct cost of capital of firms in the oil sector; crucial for capital budgeting decisions and the valuation of mergers and acquisitions; and pivotal for asset management professionals who continue to develop quantitative factor models to make investment and asset allocation decisions. Asset pricing is one of the areas in financial economics with a high impact on the financial industry. Our paper contributes to the literature by providing evidence that industry specificities are relevant to asset pricing.

\section{DECLARATION OF INTEREST}

The authors report no conflicts of interest. The authors alone are responsible for the content and writing of the paper.

\section{ACKNOWLEDGEMENTS}

The authors thank an anonymous referee and the editor for several useful comments. Helena Veiga gratefully acknowledges financial support from the Spanish Ministry of Education and Science, and the Ministry of Economy and Competitiveness, research projects ECO2012-3240, ECO2015-70331-C2-2-R and ECO2015-65701-P. Sofia Ramos acknowledges support from BRU-UNIDE, Instituto Universitário de Lisboa (ISCTE-IUL), Portugal.

\section{REFERENCES}

Adrian, T., Friedman, E., and Muir, T. (2015). The cost of capital of the financial sector. Discussion Paper DP11031, CEPR.

Al-Mudaf, A., and Goodwin, T. H. (1993). Oil shocks and oil stocks: evidence from the 1970s. Applied Economics 25(2), 181-190 (http://doi.org/dh8bzd).

Ang, A., Chen, J., and Xing, Y. (2006). Downside risk. Review of Financial Studies 19, 1191-1239 (http://doi.org/cpc9m8).

Asness, C., Porter, R., and Stevens, R. (2000). Predicting stock returns using industryrelative firm characteristics. Working Paper, Social Science Research Network.

Baek, S., and Bilson, J. F. (2015). Size and value risk in financial firms. Journal of Banking and Finance 55, 295-326 (http://doi.org/bvsv).

Ball, R. (1978). Anomalies in relationships between securities' yields and yield-surrogates. Journal of Financial Economics 6, 103-126 (http://doi.org/c82wb4).

Banz, R. (1981). The relationship between return and market value of common stock. Journal of Financial Economics 9, 3-18 (http://doi.org/d98sh4).

Barberis, N., Shleifer, A., and Vishny, R. (1998). A model of investor sentiment. Journal of Financial Economics 49, 307-343 (http://doi.org/cmm6jk).

Basu, S. (1977). Investment performance of common stocks in relation to their priceearnings ratios: a test of the efficiency market hypothesis. Journal of Finance 32, 663682 (http://doi.org/bphj). 
Basu, S. (1983). The relationship between earnings yield, market value and return for NYSE common stocks: further evidence. Journal of Financial Economics 12, 129-156 (http:// doi.org/cdqgtf).

Benth, F. E., and Meyer-Brandis, T. (2009). The information premium for non-storable commodities. The Journal of Energy Markets 2, 111-140 (http://doi.org/br79).

Bhandari, L. (1988). Debt-equity ratio and expected common stock returns: empirical evidence. Journal of Finance 43, 507-528 (http://doi.org/bvsw).

Black, F. (1972). Capital market equilibrium with restricted borrowing. Journal of Business 45, 444-454 (http://doi.org/dpww8b).

Blitz, D., Huij, J., and Martens, M. (2011). Residual momentum. Journal of Empirical Finance 18, 506-521 (http://doi.org/dpww8b).

Boyer, M. M., and Filion, D. (2007). Common and fundamental factors in stock returns of Canadian oil and gas companies. Energy Economics 29, 428-453 (http://doi.org/bjh3jf).

Carhart, M. M. (1997). On persistence in mutual fund performance. Journal of Finance $\mathbf{5 2}$, 57-82 (http://doi.org/bphf).

Chen, N. F., Roll, R., and Ross, S. (1986). Economic forces and the stock market. Journal of Business 59, 383-327 (http://doi.org/c3rrg4).

Chordia, T., and Shivakumar, L. (2006). Earnings and price momentum. Journal of Financial Economics 80, 627-656 (http://doi.org/cx2bnm).

Chordia, T., Roll, R., and Subrahmanyam, A. (2000). Commonality in liquidity. Journal of Financial Economics 56, 3-28 (http://doi.org/cp5qg9).

Chordia, T., Roll, R., and Subrahmanyam, A. (2001). Market liquidity and trading activity. Journal of Finance 56, 501-530 (http://doi.org/bf4vr5).

Chou, P. H., Ho, P. H., and Ko, K. C. (2012). Do industries matter in explaining stock returns and asset-pricing anomalies? Journal of Banking and Finance 36, 355-370 (http://doi .org/fcmm72).

Cohen, R., Polk, C., and Vuolteenaho, T. (2003). The value spread. Journal of Finance 58, 609-641 (http://doi.org/bh6rv8).

De Bondt, W., and Thaler, R. (1985). Does the stock market overreact? Journal of Finance 40, 793-805 (http://doi.org/bc7kpt).

Driesprong, G., Jacobsen, B., and Maat, B. (2008). Striking oil: another puzzle. Journal of Financial Economics 89, 307-327 (http://doi.org/c57hmv).

El-Sharif, I., Brown, D., and Burton, B. (2005). Evidence on the nature and extent of the relationship between oil prices and equity values in the UK. Energy Economics 27, 810-830 (http://doi.org/cvfz7z).

Elyasiani, E., Mansur, I., and Pagano, M. (2007). Convergence and risk-return linkages across financial services firms. Journal of Banking and Finance 31, 1167-1190 (http:// doi.org/cbchkf).

Faff, R., and Brailsford, T. (1999). Oil price risk and the Australian stock market. Journal of Energy Finance and Development 4, 69-87 (http://doi.org/fdgnzn).

Fama, E., and French, K. (1992). The cross-section of expected stock returns. Journal of Finance 47, 427-465 (http://doi.org/bpg8).

Fama, E., and French, K. (1993). Common risk factors in the returns on stocks and bonds. Journal of Financial Economics 33, 3-56 (http://doi.org/dnwhxx).

Fama, E., and French, K. (1996). Multifactor explanations of asset pricing anomalies. Journal of Finance 51, 55-84 (http://doi.org/bmnx). 
Fama, E., and French, K. (2008). Average returns, B/M, and share issues. Journal of Finance 63, 2971-2995 (http://doi.org/bb2vmq).

Fama, E., and MacBeth, J. (1973). Risk, return, and equilibrium: empirical tests. Journal of Political Economy 71, 607-636 (http://doi.org/cqm8vp).

Ferson, W., and Harvey, C. (1994). An exploratory investigation of the fundamental determinants of national equity market returns. In The Internationalization of Equity Markets, Frankel, J. (ed). University of Chicago Press.

French, K. (1980). Stock returns and the weekend effect. Journal of Financial Economics 8, 55-69 (http://doi.org/b4pvnz).

Gandhi, P., and Lustig, H. (2015). Size anomalies in US bank stock returns. The Journal of Finance 70, 733-768 (http://doi.org/bvsx).

Gibbons, M., Ross, S., and Shanken, J. (1989). A test of the efficiency of a given portfolio. Econometrica 57, 1121-1152 (http://doi.org/dp2b3v).

Hamao, Y. (1989). An empirical examination of the arbitrage pricing theory using Japanese data. Japan and the World Economy 1, 45-61 (http://doi.org/b6p46w).

Hammoudeh, S., and Li, H. (2004). The impact of the Asian crisis on the behavior of US and international petroleum prices. Energy Economics 26, 135-160 (http://doi.org/dmbddb).

Harvey, C. R., Liu, Y., and Zhu, H. (2016). ... and the cross-section of expected returns. Review of Financial Studies, forthcoming (http://doi.org/bvsz).

Hong, G., and Sarkar, S. (2008). Commodity betas with mean reverting output prices. Journal of Banking and Finance 32, 1286-1296 (http://doi.org/bhk4tm).

Hong, H., and Stein, J. C. (1999). A unified theory of underreaction, momentum trading, and overreaction in asset markets. Journal of Finance 54, 2143-2184 (http://doi.org/ c2b7sf).

Hou, K. (2003). Industry information diffusion and the lead-lag effect in stock returns. Working Paper, Ohio State University.

Hou, K., and Robinson, D. (2006). Industry concentration and average stock returns. Journal of Finance 61, 1927-1956 (http://doi.org/dxg6kv).

Hou, K., Hirshleifer, D., and Teoh, S. (2012). The accrual anomaly: risk or mispricing? Management Science 58(2), 320-335 (http://doi.org/fbcg2r).

Huang, R., Masulis, R., and Stoll, H. (1996). Energy shocks and financial markets. Journal of Futures Markets 16, 1-27. (http://doi.org/dkmrbf).

Jaffe, J., Keim, D., and Westerfield, R. (1989). Earnings yields, market values and stock returns. Journal of Finance 45, 135-148 (http://doi.org/bvs2).

Jegadeesh, N. (1990). Evidence of predictable behavior of security returns. Journal of Finance 45, 881-898 (http://doi.org/bvs3).

Jegadeesh, N., and Titman, S. (1993). Returns to buying winners and selling losers: implications for stock market efficiency. Journal of Finance 48, 65-92 (http://doi.org/ bpg6).

Jegadeesh, N., and Titman, S. (2001). Profitability of momentum strategies: an evaluation of alternative explanations. Journal of Finance 56, 699-720 (http://doi.org/b59shm).

Knez, P. J., and Ready, M. J. (1997). On the robustness of size and book-to-market in cross-sectional regressions. Journal of Finance 52, 1355-1382 (http://doi.org/bvs4).

Lewellen, J., Nagel, S., and Shanken, J. (2010). A skeptical appraisal of asset pricing tests. Journal of Financial Economics 96, 175-194 (http://doi.org/fhdrt5). 
Lin, X., and Zhang, L. (2013). The investment manifesto. Journal of Monetary Economics 60, 351-366 (http://doi.org/bwx6).

Lintner, J. (1965). The valuation of risk assets and the selection of risky investments in stock portfolios and capital budgets. Review of Economics and Statistics 47, 13-37 (http://doi .org/czs47f).

Liu, L. X., and Zhang, L. (2008). Momentum profits, factor pricing, and macroeconomic risk. Review of Financial Studies 21, 2417-2448 (http://doi.org/dtgjgk).

Merton, R. C. (1973). An intertemporal capital asset pricing model. Econometrica 41, 867887 (http://doi.org/cm9mg4).

Miller, M. (1999). The history of finance. Journal of Portfolio Management 25, 95-101 (http:// doi.org/c4w67r).

Moskowitz, T. J., and Grinblatt, M. (1999). Do industries explain momentum? Journal of Finance 54, 1249-1290 (http://doi.org/dph6xj).

Novy-Marx, R. (2013). The other side of value: the gross profitability premium. Journal of Financial Economics 108, 1-28 (http://doi.org/bhv5).

Oberndorfer, U. (2009). Energy prices, volatility, and the stock market: evidence from the Eurozone. Energy Policy 37, 5787-5795 (http://doi.org/cgtbbx).

Park, J., and Ratti, R. A. (2008). Oil price shocks and stock markets in the US and 13 European countries. Energy Economics 30, 2587-2608 (http://doi.org/dq8zdn).

Pastor, L., and Stambaugh, R. F. (2003). Liquidity risk and expected stock returns. Journal of Political Economy 111, 642-685 (http://doi.org/bjf54z).

Polk, C., Thompson, S., and Vuolteenaho, T. (2006). Cross-sectional forecasts of the equity premium. Journal of Financial Economics 81, 101-141 (http://doi.org/bghkcm).

Ramos, S. B., and Veiga, H. (2011). Risk factors in oil and gas industry returns: international evidence. Energy Economics 33, 525-542 (http://doi.org/b4wcrv).

Ramos, S. B., Veiga, H., and Wang, C. W. (2014). Risk factors in the oil industry: an upstream and downstream analysis. In The Interrelationship Between Financial and Energy Markets, pp. 3-32. Springer (http://doi.org/bvzh).

Reinganum, M. R. (1983). The anomalous stock market behavior of small firms in January: empirical tests for tax-loss selling effects. Journal of Financial Economics 12, 89-104 (http://doi.org/brxfgd).

Roll, R. (1983). On computing mean returns and the small firm premium. Journal of Financial Economics 12, 371-386 (http://doi.org/cb6376).

Rosenberg, B., Reid, K., and Lanstein, R. (1985). Persuasive evidence of market inefficiency. Journal of Portfolio Management 11, 9-17 (http://doi.org/b3zjcs).

Sadorsky, P. (2001). Risk factors in stock returns of Canadian oil and gas companies. Energy Economics 23, 17-21 (http://doi.org/bfbd77).

Shanken, J. (1992). On the estimation of beta-pricing models. Review of Financial Studies 5, 1-33 (http://doi.org/dcxnhm).

Sharpe, W. (1964). Capital asset prices: a theory of market equilibrium under conditions of risk. Journal of Finance 19, 425-442 (http://doi.org/bhzm).

Stattman, D. (1980). Book values and stock returns. Chicago MBA: A Journal of Selected Papers 4, 25-45.

Veraart, A. E., and Veraart, L. A. (2013). Risk premia in energy markets. The Journal of Energy Markets 6, 91-132 (http://doi.org/bvs6). 
108 S. B. Ramos et al

Viale, A., Kolari, J., and Fraser, D. (2009). Common risk factors in bank stocks. Journal of Banking and Finance 33, 464-472 (http://doi.org/fsnnbs).

Zeng, L., Yong, H., Treepongkaruna, S., and Faff, R. (2014). Is there a banking risk premium in the US stock market? Journal of Financial Management, Markets and Institutions 2, 27-42 (http://doi.org/bvs5). 